\title{
ESTABLISHING AN AIR POLLUTION MONITORING NETWORK FOR INDUSTRIAL REGIONS: A PROBABILISTIC APPROACH
}

\author{
Alexander RYAZANTSEV and Inna SKARGA-BANDUROVA
}

\begin{abstract}
The paper examines the issue of establishing a monitoring network for regions with highly developed industrial infrastructure. The goal is to create a unified information and analytical system that would provide for efficient environmental risk management. These results are part of a multi-year research project pursuing the ultimate goal of enhanced ecological safety in industrialised regions. We build on studies initiated by the Canadian Institutes of Health Research ${ }^{1}$ which, however, requires a large number of monitoring stations to measure the flows of pollutants with fine-scale spatial variability. In our approach we emphasise the power of the probabilistic approach to defining the location of monitoring stations and consequent efficient risk management.
\end{abstract}

Keywords: Environmental safety, risk management, monitoring network, probability of emission detection, unified information system, monitoring station, location, pollution detection.

\section{Introduction}

Efficient risk management requires as much information as possible. Continuous emissions monitoring of certain chemical productions illustrates one of ways to collect information. ${ }^{2}$ Continuing to gather information on the chemicals themselves is equally important. ${ }^{3}$ The received information can be used to identify dangers or it can help to develop environmental policy of regions. The goal of environmental policy is to limit, slow-down, reduce or eliminate environmental damages caused by industrial and human activities. ${ }^{4}$ If the general quantity of a pollution agent is less than quota, there emerges a reserve in an environmental risk management. If the deviation is to the bigger side, the environmental risk increases and should be reconsidered for making decisions on decreasing the general load to the environment.

Emissions of industrial enterprises stipulated by implementation of technological processes and regulated by production capacities, are predictable but require continuous or non-continuous monitoring for defining the level of deviation of regulated quantities of a pollution agent. 


\section{Defining Problem and Goals for Creation of a Monitoring Network}

Monitoring of fixed sources of a pollution agent can be partially conducted with using fixed air quality control stations. In connection with high value of implementation and operation of such stations as well as stochastic nature of admixture distribution in the atmosphere, the efficiency of operation of a group of fixed stations of the region significantly depends on their location. On the one hand it is necessary to select the number of such stations and their location that during the regulation time of observations the probability of detection the concentration of emissions over MAC was not lower than the established tolerance interval (usually $95 \%$ detection probability for a number of fixed stations is selected), on the other hand, the value of operation of all stations during the regulation time should not exceed the expected damage from determined sources of pollution, otherwise operation of such stations is not economically efficient. There is an optimization problem with the following criteria:

1. Cumulative probability of detecting pollution by a group of fixed stations should be not less than the established value TI (usually 0.95): $P_{\Sigma} \geq T I$;

2. Location of fixed stations in places of the most probable detection of emission with taking into account a wind rose, typical for this locality, for multiple fixed stations should represent all sources of pollution to the maximum;

3. Cumulative operation value of all stations of fixed surveillance $\mathrm{Se}$ should not exceed the total expected damage $M s$ from concerned fixed stations of pollution agents: $\mathrm{Se} \leq \mathrm{Ms}$.

Operating value of fixed surveillance stations during the regulation time is defined by virtue of the value of emissions quota and the amount of fine sanctions of their excess. As the value of exceeding the quota for a forecasting period is not known, it is allowed to take it as equal to the amount of excess for the previous reporting period. Over-quota emissions from fixed stations for a forecasting period can be referred to the stochastic component of pollutants.

\section{Framework Process for Optimization of Structure of a Monitoring Network}

For defining the location of a network of fixed surveillance stations it is necessary to receive a field of space distribution of detection probability of exceeding MAC concentrations. To do this, models of admixtures distribution in the atmosphere from fixed stations, ${ }^{5}$ with the help of which space-time distribution of admixtures concentration as preset conditions of emissions for a certain source of a pollution admixture.

Input data for simulation of distribution of concentrations in space is stochastic:

- $\quad$ wind direction; 
- wind velocity;

- atmosphere stability (inversion, convection, isothermy);

- pollution source power, etc.

Each stochastic $i$-th parameter is featured by detection probability within the limits of some ranges of its changing. Any set of probable input data excludes display of another set, that is, united by logical connection "excluding OR". It means that if a vector of phase variables $\vec{\Psi}_{i}$ of input data for each source, their values is distributed with various probabilities by ranges of full set of values. For example, wind direction has a probability in conformity with a wind rose of this locality. There is data for 4,8 and 16 sections (ranges). The most widespread data for 8 sections, but it is preferable for 16. It is reasonable to present a wind rose by two tables for wind directions and velocities (Table 1, Table 2).

During simulation values in brackets are inserted. It is recommended to use fixed number of wind velocities range presented in the table. At wind velocity over $6 \mathrm{~m} / \mathrm{s}$ the intensity of clouds dissipation is rather high and its danger is significantly diminished. The total conditional probability of implementation of the set of input parameters is defined as:

$$
P_{j}=\prod_{k=1}^{N} P_{k},
$$

where $N=\sum_{u} r_{u}$ - is the total number of independent input parameters, defining the intensity of spreading the pollutant in space.

Table 1. Wind Directions.

\begin{tabular}{clcc}
\hline Sector, degree & \multicolumn{1}{c}{ Name } & Direction, degree & Probability \\
\hline $337.5-22.5$ & South & 0 & $\ldots$ \\
$22.2-67.5$ & South-West & 45 & $\ldots$ \\
$67.5-112.5$ & West & 90 & $\ldots$ \\
$112.5-157.5$ & North-West & 135 & $\ldots$ \\
$157.5-202.5$ & North & 180 & $\ldots$ \\
$202.5-247.5$ & North-East & 225 & $\ldots$ \\
$247.5-292.5$ & East & 270 & $\ldots$ \\
$292.5-337.5$ & South-East & 315 & $\ldots$ \\
\hline & & & Sum: \\
\hline
\end{tabular}


Table 2. Wind Velocity.

\begin{tabular}{cc}
\hline Wind velocity range, $m p s$ & Probability \\
\hline$\leq 2(1)$ & $\ldots$ \\
$2<U \leq 3(2.5)$ & $\ldots$ \\
$3<U \leq 5(4)$ & $\ldots$ \\
$5<U \leq 6(5.5)$ & $\ldots$ \\
$>6(6)$ & $\ldots$ \\
\hline & Sum:
\end{tabular}

The total probability of defining concentration exceeding MAC is calculated as:

$$
P_{\text {MAC }}=\sum_{\mathrm{j}=1}^{\mathrm{F}}\left(\prod_{k=1}^{N} P_{k}\right)_{j},
$$

where $F=\prod_{u} r_{u}$ is the number of possible combinations of independent input parameters.

For example, for a single pollution source the total field of conditional probability of detection of concentrations exceeding MAC (under condition of implementation of emissions of a preset capacity from this source), limited by the lower probability with the order 0.005 is shown on Figure 1.

The dash line limits the territory inside of which the probability of emissions detection from this source exceeds the minimal 0.005 , the heavy dash line marks space, the probability of pollutant detection in which exceeds the minimal acceptable 0.05 . Descending assortment of probabilities (field of probability) allows distinguishing the set of coordinates for which the total probability $P_{\Sigma} \geq 0.95$. At this the set of at least 4 fixed stations is necessary. The most rational location of these stations is marked on Figure 2. Similar calculations are conducted for each group of probable pollutants.

If multiple fixed sources of pollution are taken into consideration, it is necessary to build the same field for all sources considered. Figure 3 shows such field for three various sources of pollution.

At this for fulfillment of condition $P_{\Sigma} \geq 0.95$ at least 9 fixed surveillance stations are required. Such number of stations for this example meets the requirement Se $\leq M s$. 


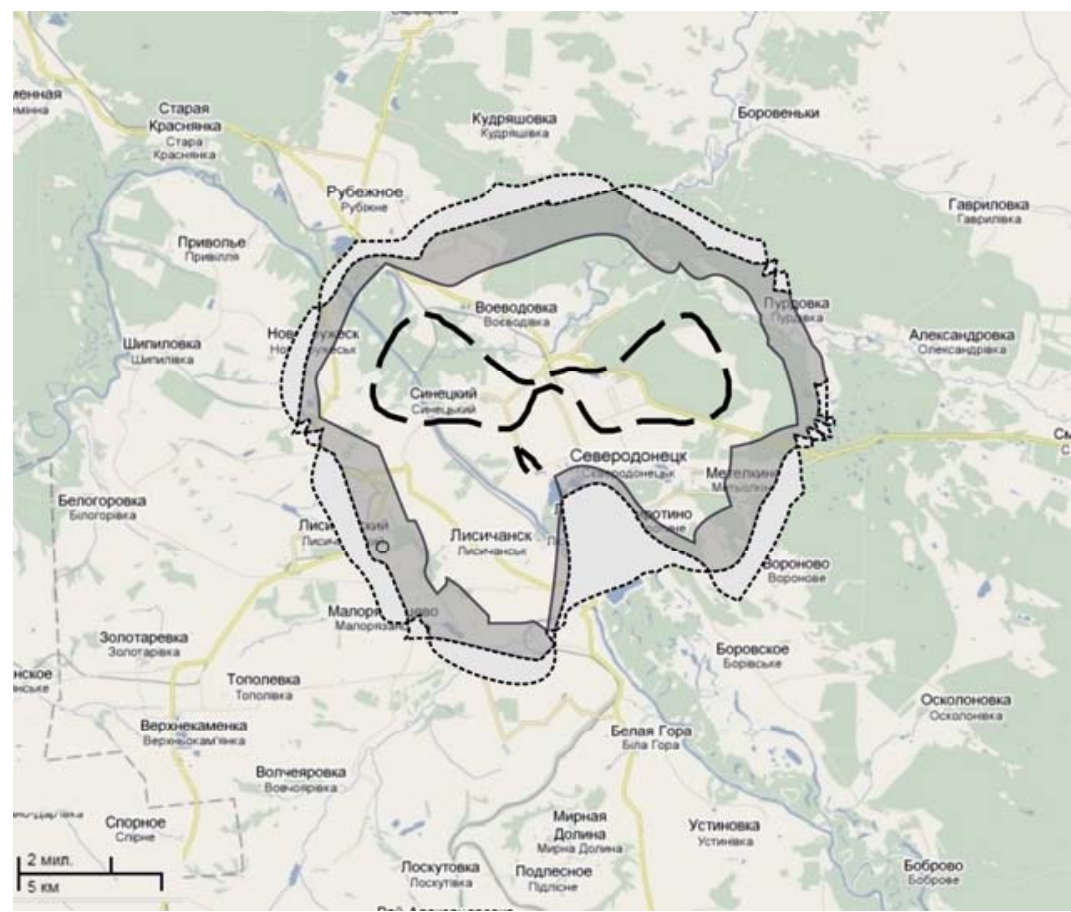

Figure 1: Probability field of detection of concentrations exceeding MAC from one source of pollution (Severodonetsk, Ukraine).

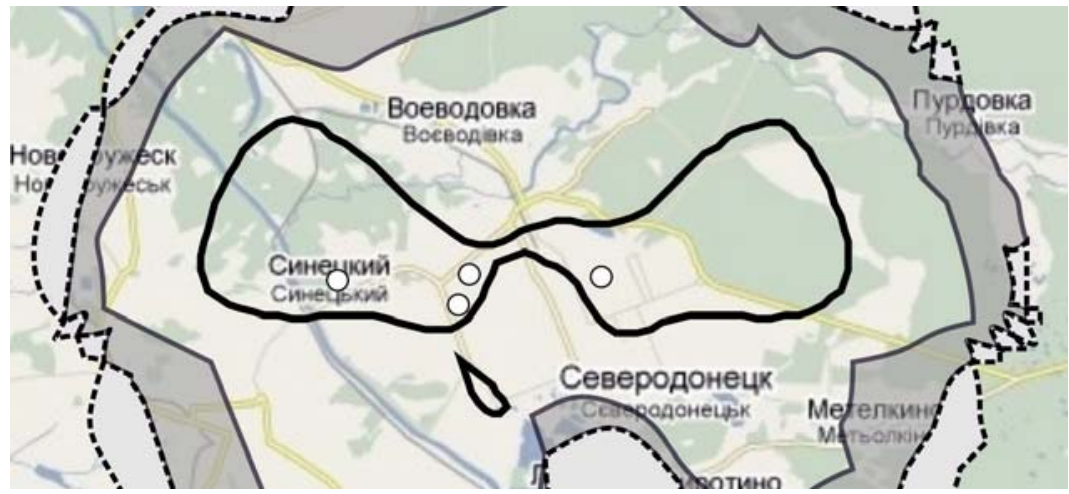

Figure 2: The most rational location of fixed stations (red circles) in space. 


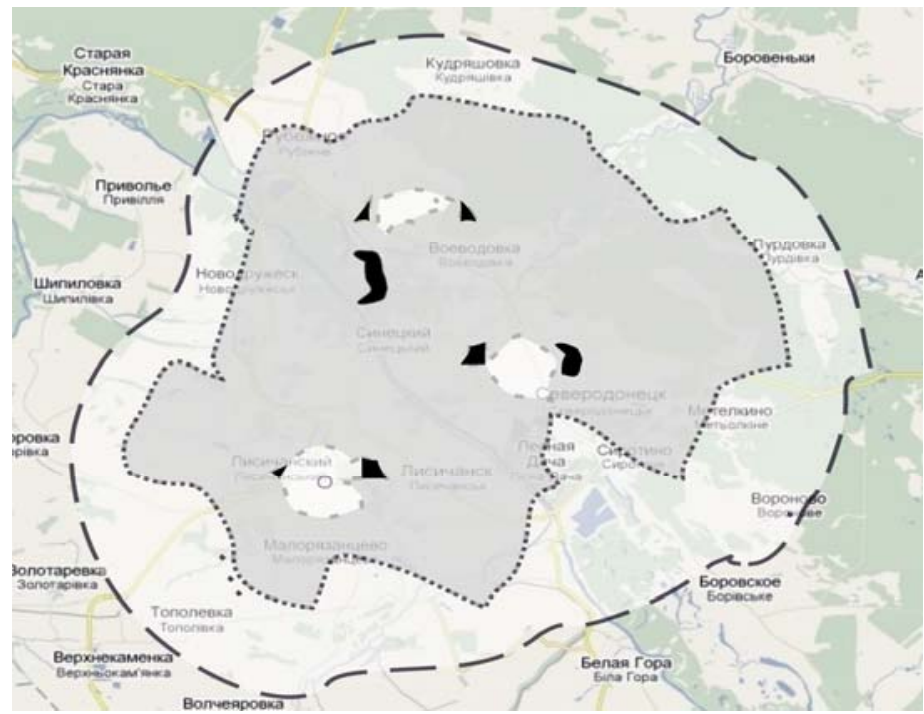

Figure 3: Probability field of detection of concentrations exceeding MAC from three various fixed sources of pollution.

For the most rational location of fixed surveillance stations with taking into consideration that the probability of detecting all three sources of pollution should be maximal, automatic search of all possible locations of the set of coordinates of stations $\left(x_{j}, y_{j}\right)$ for the function $\min \left(\sum_{j}\left(\sum_{b}\left(l\left(x_{j}, y_{j}\right)\right)_{b}\right)_{j}\right):$ the sum of all distances from each fixed station to the place of location of each fixed source of pollution should be minimal. The final location of stations at solving this example is shown on Figure 4.

\section{Conclusion}

It is remarkable that at selection of the number of stations and their location for each single source of emissions, the given example requires not fewer than 4 stations, which is stipulated by the same wind rose for this locality and approximate similarity of capacity of sources of pollution. If all fixed emission control stations from all sources considered are used, at saving the tolerance interval of emissions detection not 12 stations are required, but only 9, under condition that location of these stations will be in places defined on Figure 4.

With increasing the number of additional pollution sources of the region depending on their location afield, optimization of expenses for fixed surveillance stations becomes more notable. The method for optimally locating monitors may have wide- 


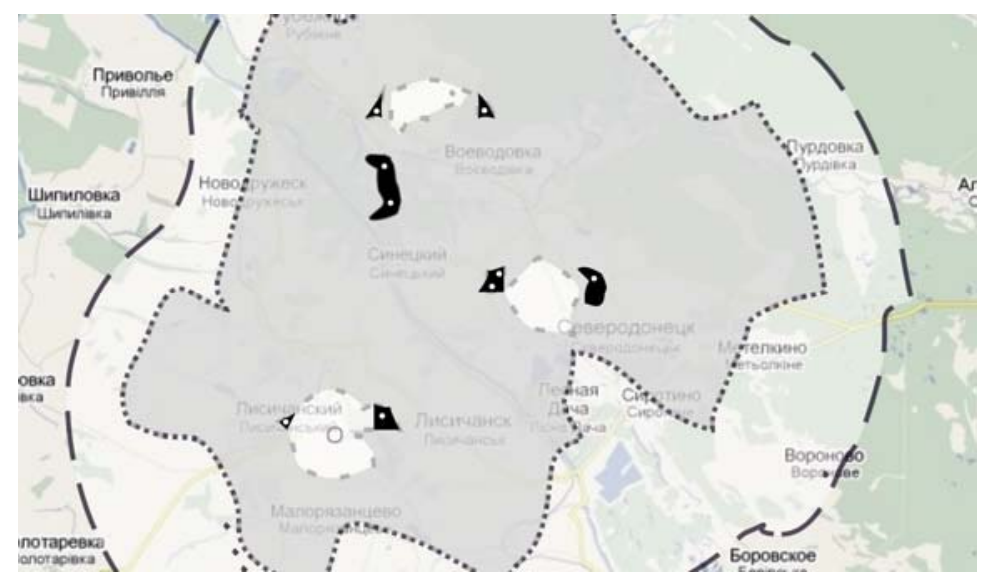

Figure 4: Places of the most rational location of fixed monitoring stations for the presented example are shown as white circles inside the black areas.

spread applicability for the design of pollution monitoring networks, particularly for measuring traffic pollutants. The method also appears to have considerable promise for improving the assessment of exposure to ambient air pollution and enables tests in morbidity level studies.

\section{Acknowledgement}

This paper reflects results of two research projects "Analysis of state and the development of the information infrastructure of technozone" conducted by the Research Laboratory at the Technological Institute of East Ukrainian National University named after Volodymyr Dahl in 2006-2010, registration number 0104U00390 and "Analysis of the existent environmental monitoring system and research of influence on the air in Severodonetsk", funded by Severodonetsk municipal council, Ukraine, 2009.

\section{Notes:}

1 Pavlos S. Kanaroglou, Michael Jerrett, Jason Morrison, Bernardo Beckerman, M. Altaf Arain, Nicolas L. Gilbert, and Jeffrey R. Brook, "Establishing an air pollution monitoring network for intra-urban population exposure assessment: a location-allocation approach," Working Paper Series 001 (Hamilton, ON: Centre for Spatial Analyses, McMaster University, October 2004)

${ }^{2}$ Harry Cendrowski and William C. Mair, Enterprise Risk Management and COSO: a Guide for Directors, Executives, and Practitioners (Hoboken, NJ: John Wiley, 2009), 4-70. 
3 A. Ian Glendon, Sharon G. Clarke, and Eugene F. McKenna, Human Safety and Risk Management (Boca Raton, FL: CRC Press, Taylor \& Francis, 2006); Kim Heldman, Project Manager's Spotlight on Risk Management (Alameda, CA: SYBEX, 2005); John D. Andrews and T. Robert Moss, Reliability and Risk Assessment, Second edition (WileyBlackwell, 2002).

4 Johannes Meijer and Arjan der Berg, eds., Handbook of Environmental Policy (Nova Science Publishers, 2011).

5 Richard Webster and Margaret A. Oliver, Statistical Methods in Soil and Land Resource Survey (Oxford: Oxford University Press, 1990); Seymour Calvert and Harold M. Englund, Handbook of Air Pollution Technology (New York, NY: John Wiley, 1984); Daniel A. Vallero, Environmental Contaminants: Assessment and Control (San Diego, CA: Elsevier Academic Press, 2004); C.J.H. van den Bosch and R.A.P.M. Weterings, eds., Methods for the calculation of physical effects - 'Yellow Book,' CPR 14E, Third edition (The Hague: Committee for the Prevention of Disasters, 1997), Chapter 3.

ALEXANDR RYAZANTSEV is Head of the Computer Engineering Department of Technological Institute of Volodymyr Dahl East Ukrainian National University, Severodonetsk, Ukraine. He graduated from the Kharkiv Institute of Radio Electronics in 1988 and received a PhD degree in Systems of designing automatization from Institute of Radio Electronics of the Ministry of Education and science of Ukraine, Kharkiv, in 1993. He has authored and co-authored of seven books and more than 40 papers published in Ukrainian refereed journals. His current research focused on developing of methodologies and information technologies for environmental and technologic safety of industrial regions. In this area he currently leads two research projects. E-mail: a_ryazancev@mail.ru.

INNA SKARGA-BANDUROVA is associate professor at the Computer Engineering Department of Technological Institute of Volodymyr Dahl East Ukrainian National University, Severodonetsk, Ukraine. She graduated from the East Ukrainian State University in 1996 and received a $\mathrm{PhD}$ degree in Computerized Control Systems and Progressive Information Technology from Donetsk National University of the Ministry of Education and Science of Ukraine, in 2006. Research interests: systems analysis, decision theory, inferencial, fuzzy and abduction reasoning, development of novel prediction and diagnosing models based on data from non-standard designs. Her current researches devoted to formal methods in information technologies for industry and medicine, functional safety of I\&C systems for critical infrastructures.E-mail: skarga-bandurova@ukr.net. 